\title{
Ältester Druck aus Villingen
}

Bei der Stuttgarter Antiquariatsmesse 2016 konnte ein für die Landesgeschichte bedeutender Druck erworben werden. Es handelt sich um das erste im damals vorderösterreichischen Villingen gedruckte Buch (HBF 10176). Das kleinformatige Erbauungsbuch „Ein Geistlich Zeuchhauß, oder Rüst Kammer für die Ordens vnd Closterleuth" von Martin Digasser aus dem Jahr 1596 richtet sich vor allem an weibliche Ordensangehörige und ist deswegen in der Volkssprache gehalten. Männliche Ordensleute wurden häufig zu Priestern ausgebildet und schrieben bzw. verstanden selbstverständlich Latein. Es handelt sich um die deutsche Übersetzung eines nicht näher benannten italienischen Werkes. Die Widmung bezieht sich auf Äbtissinnen der franziskanischen Ordensfamilie im vorderösterreichischbayerischen Raum, darunter auch an Apollonia Moser, von 1591 bis 1612 Äbtissin des KlarissenKonvents in Villingen. Der erste Teil des 55 Blatt umfassenden Buches analysiert unterschiedliche Arten von Versuchungen im Ordensleben und beschreibt Maßnahmen zu deren Bewältigung. Der zweite Teil ist kürzer und enthält zehn Gebete, die als praktische Konkretion dem ebenfalls in zehn Kapitel gegliederten ersten Teil entsprechen. Der

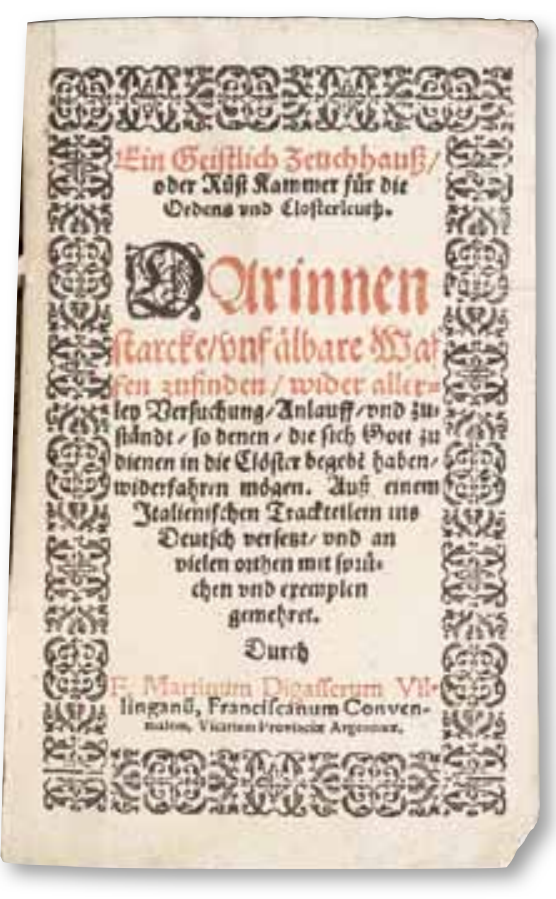

zweite Teil wird zudem veranschaulicht durch drei Holzschnitte mit traditionellen Motiven (Anna Selbdritt, Beweinung des gekreuzigten Christus, Schweißtuch der Veronika).

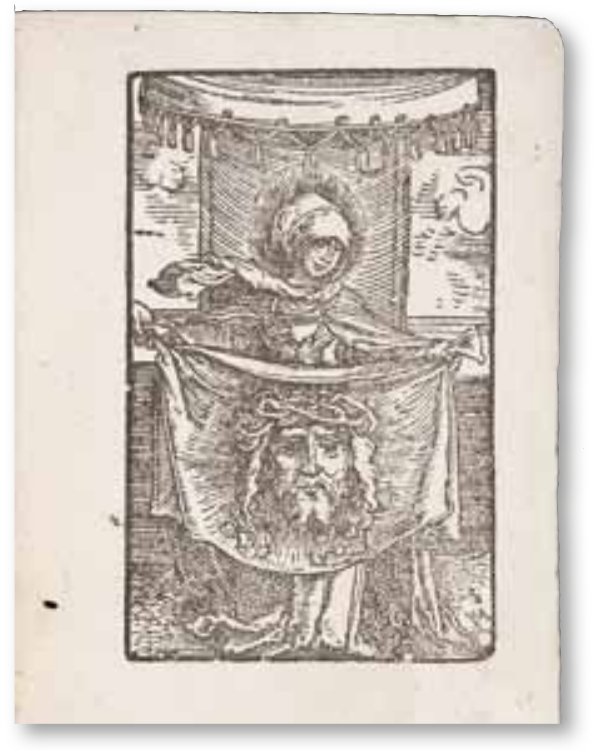

Abb. 2: Schweißtuch der Veronika

Martin Digasser (gestorben ca. 1607/1608) war als Provinzvikar der Franziskaner mit der Region vertraut und wurde 1601 Pfarrer in Villingen.

Zum Buchdruck im abgelegenen Schwarzwaldort kam es, weil die Universität Freiburg wegen drohender Pestepidemien mehrfach, so auch 15941595, nach Villingen verlagert wurde. Buchdrucker hatten Absatzchancen vor allem in freien Reichsstädten, Residenz- und Universitätsstädten. Der später nicht mehr in Erscheinung tretende Drucker Egidius Reitter erkannte die kommerziellen Möglichkeiten des universitätsnahen Buchdrucks, kam wegen der Rückverlagerung der Universität nach Freiburg aber nicht über den Druck dieses Erbauungsbuches hinaus. Es diente möglicherweise als Erstlingswerk der Druckereiwerkstatt zur Erprobung der Technik, bevor Investitionen zur Herstellung umfangreicher wissenschaftlicher Schriften getätigt worden wären.

Auf dem Vorsatzblatt findet man den handschriftlichen Besitzvermerk einer Nonne. Für die Erstellung des Einbands wurde vermutlich aus Klosterbesitz eine Pergamenthandschrift zerschnitten. 